\title{
Theofilos
}

A Nordic open access journal in Theology, Philosophy and Culture

Published by NLA University College - in partnership with Johannelund School of Theology

Available at www.theofilos.no

enige, men nytt lys over diskusjonen kan resultere i økende respekt for andres syn. Det igjen vil senke temperaturen i en ofte opphetet debatt. Lys er ofte bedre enn hete når det gjelder meningsutveksling.
${ }^{1}$ En lengre versjon av denne artikkelen er tidligere publisert i Fodrelandsvennen 13/1-21 og i Dagen 4/2-21.

\author{
Kåre Melhus \\ Førstelektor emeritus \\ NLA Høgskolen, Kristiansand \\ karemelhus@gmail.com
}

\section{I dette nummer ...}

Velkommen til den første ordinære utgaven av Theofilos som open access tidsskrift. Vi håper at mange av våre lesere har hatt utbytte av det innholdsrike temanummeret om «Science, Natural Theology, and Christian Apologetics». ${ }^{1}$ Det er nå en glede å kunne presentere et omfattende dobbeltnummer med bredde, dybde og aktualitet.

Demokratiet fungerer best når vi evner å respektere andre, samtidig som vi søker å fremme våre egne overbevisninger med åpne premisser og saklige argumenter. Denne betimelige påminnelsen fra Kåre Melhus i vår innledende lederartikkel, gjelder også et tidsskrift som Theofilos. Derfor løfter vi også frem betydningen av gode forskningsetiske og publiseringsetiske holdninger på theofilos.no. ${ }^{2}$

De tre første artiklene i academia omhandler sentrale kristne personligheter $\mathrm{i}$ Norden på 1800-tallet. I anledning 150årsjubileet av Landstads Kirkesalmebok i 2020, presenterer Egil Sjaastad en analyse av eskatologien i salmene til den norske dikteren. På bakgrunn av en undersøkelse av utvalgte prekenutkast, gir Torbjörn Larspers et bilde av den svenske vekkelseslederen Carl Olof Rosenius som forkynner. Tomas Bokedal drøfter danske Søren Kierkegaards kommunikasjonsstrategi i sitt forfatterskap, med vekt på direkte-indirekte meddelelse og den kristne troens hvordan.

I neste bidrag beveger vi oss nærmere vår egen tid. Simeon Ottosen foretar her en sammenligning av argumentasjonen for Bibelens ufeilbarlighet hos den norske teologen Carl Fredrik Wisløff og «Chicago Statement on Biblical Inerrancy».

Academia avrundes med tre artikler som omhandler dagsaktuelle temaer. Joel Halldorf analyserer Sverigedemokraterna som et høyrepopulistisk parti, ut fra flytende modernitet, eksistensiell angst og relasjonen til faste kirkegjengere som perspektiv. Profetiene om Donald Trump, USA og Guds rike innenfor New Apostolic Reformation-bevegelsen står i fokus i Arne Helge Teigens kritiske undersøkelse. I den siste artikkelen er vi over i kirkerommets verden. Hans-Olav Hodøl drøfter her bruken av digital presentasjonsteknikk i gudstjenester, og inkluderer også noen praktiske råd.

Per-Axel Sverker innleder forum-delen av dette nummeret med en artikkel om John Stott som «evangelikal kirkefader». I april 2021, er det 100 år siden den profilerte britiske forfatteren, forkynneren og misjonslederen ble født. I neste bidrag foretar Fernando Vasques en sammenligning mellom Francis Jonbäcks Meningsfullt liv og Martin Hägglunds Vårt enda liv: sekulär tro och andlig fribet, med utgangspunkt i spørsmålet hvorvidt ateismen kan være eksistensielt relevant.

Olof Edsinger presenterer så en bibelteologisk drøfting av uttrykket «mannen som kvinnens hode», med en intensjon 
om «en eksegetisk og praktisk mellomvei». Den lutherske veteranapologeten John Warwick Montgomery publiserte i 2018 en introduksjonsbok til apologetikk, og i neste artikkel møter vi en kritisk analyse av Montgomerys argumentasjon fra Peter S. Williams. Den avgåtte amerikanske presidenten er igjen tema i den påfølgende artikkelen, med Kjell O. Lejon som skribent, utfra stikkordene støtte, kritikk og kulturkamp.

De siste artiklene i forum er fra to profilerte kvinnelige bidragsytere. Begge bidragene re-publiseres her med tillatelse. Mens den amerikanske litteraturprofessoren Karen Swallow Prior drøfter betydningen av fiksjonslitteratur for det kristne livet, gir dekan og teologiprofessor Aud V. Tønnesen en innføring i sentral kirkelig kritikk av velferdsstaten.

Dette dobbeltnummeret inneholder selvsagt også bokanmeldelser. De ti bøkene som er anmeldt i biblos, representerer en betydelig bredde i fagfelt, tematikk og sjanger. Bidragene er behørig introdusert av bokredaktør Bjørn Hinderaker.

Neste nummer (2021/1) planlegges utgitt i juni. I mellomtiden kan det være naturlig å minne om at alle tidligere utgaver er tilgjengelige online. En utforsking av theofilos.no anbefales, - med gode muligheter for betydelig faglig og personlig utbytte!

Tidsskriftets faglige nisje er «studier av teologi, filosofi og kultur og beslektede fagfelt», mens den overordnede hensikt er å "presentere, analysere og drøfte den kristne troens sannhet og relevans». Som redaksjon er vi overbevist om at tidsskriftets nisje og hensikt fortsatt er like relevante, samtidig som vårt nylig etablerte open access format gir nye muligheter for god profilering.

På nettsiden vår siterer vi Oxford-teologen Alister E. McGraths treffende utsagn om apologetikk som science and art. I Mere Apologetics (2012) oppsummerer han "the three tasks faced by apologists of the past and present under three main headings: defending, commending, and translating". Han utvikler dette som "... identifying and responding to objections concerning the gospel, ... communicating the excitement and wonder of the Christian faith, ... and translating the core ideas of the Christian faith into language that makes sense to outsiders".

Vi håper også dette nummeret skal bidra til faglig refleksjon, inspirasjon og samtale rundt disse sentrale apologetiske oppgavene. God lesing!

$$
\begin{gathered}
\text { Lars Dahle } \\
\text { ansvarlig red. } \\
\text { NLA Høgskolen, Kristiansand } \\
\text { lars.dable@nla.no }
\end{gathered}
$$

1. Se https://theofilos.no/issues/theofilossupplement-2020-1/.

2. Se https://theofilos.no/open-access/. 